\title{
Macular Changes after Uneventful Phacoemulsification in Diabetic Patients in a Tertiary Hospital
}

\author{
Maaly Abdel Halim Abdel Fattah ${ }^{1,2^{*}}$, Faisal Mesfer Alqahtani ${ }^{2}$ and Selwa Abdullah Alhazzaa ${ }^{2}$ \\ ${ }^{1}$ Department of Ophthalmology, Cairo University, Egypt \\ ${ }^{2}$ Department of Ophthalmology, King Faisal Specialist Hospital \& Research Center, Saudi Arabia
}

*Corresponding author: Maaly Abdel Halim Abdel Fattah, King Faisal

Specialist Hospital \&Research Center, Saudi Arabia.

Received Date: September 17, 2018

Published Date: September 26, 2018

\begin{abstract}
Purpose was to evaluate the subclinical influence of uncomplicated phacoemulsification surgery on foveal thickness in the early postoperative period.

Materials and methods: This study was conducted on 50 eyes of 44 subjects who underwent uneventful phacoemulsification in King Faisal Specialist Hospital and Research center (KFSH\&RC). They were divided into

Groups: Diabetes mellitus group consisted of 25 eyes ( 21 diabetic patients), Control group consisted of 25 eyes ( 23 non-diabetic patients). Best corrected visual acuity and Optical coherence tomography were recorded preoperatively, 2 weeks, one month and two months postoperative.

Results: Despite that Mean foveal thickness was stable 2 weeks, 1 month and 2 months postoperative in the control group; our study showed significant increase in mean foveal thickness (MFT) 1 month and 2 months post-operative in diabetic group compared to the 2nd week postoperative. However, after converting the MFT into Log OCT, the MFT in diabetic and control groups was stable postoperatively without any step deterioration.
\end{abstract}

Conclusion: Diabetic patients may need prophylactic therapy before cataract surgery.

Keywords: Macular edema; Phacoemulsification; Optical coherence tomography; Diabetes mellitus

Abbreviations: KFSH\&RC: King Faisal Specialist Hospital \& Research Center; OCT: Optical Coherence Tomography; BCVA: Best Corrected Visual Acuity; DR: Diabetic Retinopathy

\section{Introduction}

The incidence of subclinical macular edema after uneventful phacoemulsification has become an issue of safety for this frequently performed operation. Advances in phacoemulsification techniques and intraocular lens design have led to improved outcomes following cataract surgery. Nevertheless, ME may develop and can result in suboptimal postoperative vision [1].

\section{Aim of the Study}

The aim of our study was to evaluate the subclinical influence of uncomplicated phacoemulsification surgery on foveal thickness in the early postoperative period.

\section{Materials and Methods}

This study was conducted on 50 eyes of 44 subjects who underwent uneventful phacoemulsification and posterior chamber
IOL implantation in King Faisal Specialist Hospital and Research center. They were divided into 2 groups: Group 1: Diabetes mellitus group consisted of 25 eyes (21 diabetic patients), Group 2: Control group consisted of 25 eyes (23 non-diabetic patients). BCVA and OCT were recorded preoperatively, 2 weeks, one month and two months postoperative. The study was approved by the institutional review board of our hospital. Any participant with preoperative central involved DME (more than $310 \mu \mathrm{m}$ on spectral domain (SD-OCT) \{Carl Zeiss Meditec\}, Eyes with major ocular surgery or received intravitreal Anti VEGV in the prior 4 months, were excluded from the study. Medical treatment for macular edema either topical or intravitreal injection was not performed during the study time. The data entry and analysis were performed using Statistical Package for the Social Sciences Program (SPSS) $23^{\text {rd }}$ Edition. 


\section{Result}

1. The mean age of control group was $68.14 \pm 6.7$ while that of the diabetic group was $64 \pm 10.126$ with a mean duration of diabetes of 16 years \pm 8.124 .

2. No diabetic retinopathy (DR) was detected preoperative in $40 \%$ of diabetic eyes. Five patients $(20 \%)$ had moderate non-proliferative diabetic retinopathy. Mild non-proliferative diabetic retinopathy was recorded in $32 \%$ of eyes of diabetic patients.

3. Proliferative diabetic retinopathy (treated with complete laser photocoagulation 2-3years before cataract surgery) was realized in 2 patients only ( $8 \%$ )

Mean Foveal Thickness (MFT) in diabetic patients was higher than control group preoperative and postoperative (2 weeks, 1 month, and 2 months) with high statistical significance difference (Table 1). Significant increase MFT 1 month and 2 months postoperative in diabetic group compared to the $2 \mathrm{nd}$ week postoperative. MFT was stable 2 weeks, 1 month and 2 months postoperative in the control group. Visual acuity is markedly improved from 0.6 to 0.2 postoperatively in all patients of group 1 and 2 at the second week postoperative. Despite there was no statistical significance difference in the VA recorded in diabetic patients at $2^{\text {nd }}$ week, $1^{\text {st }}$ month and 2 nd month postoperative but statistical significance difference was noted in group 2 as the visual acuity improved to 0.2 in the $2^{\text {nd }}$ week then showed one line improvement in the $1^{\text {st }}$ month and $2^{\text {nd }}$ month postoperative as described.

Table 1: Comparison between diabetics \& control groups regarding log OCT.

\begin{tabular}{|c|c|c|c|}
\hline Log OCT & DM (n=25) & Control $(n=25)$ & $P$ value \\
\hline Preoperative & $\begin{array}{l}263.52 \pm 57.3 \\
\log 263 / 200 \\
\quad=0.11\end{array}$ & $\begin{array}{l}221.44 \pm 25 \\
\log 221 / 200 \\
\quad=0.043\end{array}$ & $0.0001 \mathrm{HS}$ \\
\hline $\begin{array}{c}2 \text { week } \\
\text { postoperative }\end{array}$ & $\begin{array}{c}263.68 \pm 62 \\
\log 263 / 200 \\
=0.11\end{array}$ & $\begin{array}{c}222.0 \pm 27.4 \\
\log 222 / 200 \\
=0.045\end{array}$ & 0.004 HS \\
\hline $\begin{array}{c}1 \text { month } \\
\text { postoperative }\end{array}$ & $\begin{array}{c}282.8 \pm 85.6 \\
\log 282 / 200 \\
\quad=0.14\end{array}$ & $\begin{array}{c}223.56 \pm 22.4 \\
\log \\
223 / 200=0.047\end{array}$ & $0.002 \mathrm{HS}$ \\
\hline $\begin{array}{c}2 \text { months } \\
\text { postoperative }\end{array}$ & $\begin{array}{c}282 \pm 95 \\
\log 282 / 200 \\
=0.14\end{array}$ & $\begin{array}{c}223.44 \pm 22.83 \\
\log 223 / 200 \\
=0.047\end{array}$ & $0.005 \mathrm{HS}$ \\
\hline
\end{tabular}

\section{Comparison between diabetics \& Control groups regarding log oct}

Logarithmic transformation of retinal thickness is a proposed method for assessing whether the observed OCT change in a patient is real; one step log scale change exceeds the measurement error for all degrees of retinal thickness in current instruments. This Logarithmic transformation of retinal thickness has a value for the follow up visits for statistical comparisons.it is calculated by taking the log base of the ratio of the central subfield thickness divided by 200 and rounding to the nearest hundredth [1]. Our results showed that after converting the MFT into Log OCT, the MFT in diabetic and control groups was stable postoperatively without any step deterioration.

\section{Changes occurred at each time Interval regarding MFT in each group}

MFT of $64 \%$ in diabetic group, $68 \%$, and $60 \%$ of eyes were stable in 2 nd week, $1^{\text {st }}$ month $\& 2^{\text {nd }}$ month postoperative respectively. 5 eyes (20\%) showed one step deterioration in the second month postoperative. only one eye showed deterioration 3 steps in the $1^{\text {st }}$ month and $2^{\text {nd }}$ month postoperative. In control group: MFT of $84 \%$, $76 \%$, and $80 \%$ of eyes were stable in 2 nd week, $1^{\text {st }}$ month $\& 2^{\text {nd }}$ month postoperative respectively. 3 eyes (12\%) showed only one step deterioration in the first month postoperative. No one showed deterioration 2 or 3 steps in the 1st or 2 nd month postoperative (Table 2).

Table 2: Showed changes occurred at each time interval regarding MFT in both groups.

\begin{tabular}{|c|c|c|c|c|c|c|}
\hline \multirow{2}{*}{$\begin{array}{l}\text { LOG OCT } \\
\text { DM Group }\end{array}$} & \multicolumn{3}{|c|}{ IThickness } & \multirow{2}{*}{$\begin{array}{l}\text { Thickness } \\
1 \text { step only }\end{array}$} & \multirow{2}{*}{$\begin{array}{l}\text { Stable } \\
\text { 0 step }\end{array}$} & \multirow{2}{*}{ Total } \\
\hline & $\underline{1}$ & $\underline{\underline{2}}$ & $\underline{\underline{3}}$ & & & \\
\hline 2nd week & 1 & 1 & 0 & 7 & $\begin{array}{c}16 \\
(64 \%)\end{array}$ & 25 \\
\hline 1st month & 4 & 1 & 1 & 2 & $\begin{array}{c}17 \\
(68 \%)\end{array}$ & 25 \\
\hline 2nd month & 5 & 2 & 1 & 2 & $\begin{array}{c}15 \\
(60 \%)\end{array}$ & 25 \\
\hline \multicolumn{7}{|c|}{ LOG OCT ControlGroup } \\
\hline 2nd week & 1 eye & 0 & 0 & 3 & $\begin{array}{c}21 \\
(84 \%)\end{array}$ & 25 \\
\hline 1st month & 3 eyes & 0 & 0 & 3 & $\begin{array}{c}19 \\
(76 \%)\end{array}$ & 25 \\
\hline 2nd month & 2 eyes & 0 & 0 & 3 & $\begin{array}{c}20 \\
(80 \%)\end{array}$ & 25 \\
\hline
\end{tabular}

\section{Comparisons between LOG MAR in both Groups}

There was no statistical significance difference in the VA (log MAR) between both diabetic patients and control group either in the $2^{\text {nd }}$ week, $1^{\text {st }}$ or $2^{\text {nd }}$ month postoperative (Table 3 ).

Table 3: Comparison between diabetics \& control group regarding MFT and BCVA.

\begin{tabular}{|c|c|c|c|}
\hline MFT & DM $(\mathbf{n = 2 5})$ & Control $(\mathbf{n}=\mathbf{2 5})$ & P value \\
\hline Preoperative & $263.52 \pm 57.3$ & $221.44 \pm 25$ & $0.0001 \mathrm{HS}$ \\
\hline 2 week postop. & $263.68 \pm 62$ & $222.0 \pm 27.4$ & $0.004 \mathrm{HS}$ \\
\hline 1 month postop. & $282.8 \pm 85.6$ & $223.56 \pm 22.4$ & $0.002 \mathrm{HS}$ \\
\hline $\begin{array}{c}2 \text { months } \\
\text { postop. }\end{array}$ & $282 \pm 95$ & $223.44 \pm 22.83$ & $0.005 \mathrm{HS}$ \\
\hline VA (Log MAR) & DM (n=25) & Control $(\mathrm{n}=25)$ & P value \\
\hline $\begin{array}{c}\text { Preoperative } \\
\text { 2 weeks } \\
\text { postoperative }\end{array}$ & $0.648 \pm 0.39$ & $0.596 \pm 0.37$ & $0.6 \mathrm{NS}$ \\
\hline $\begin{array}{c}1 \text { month } \\
\text { postoperative }\end{array}$ & $0.220 \pm 0.2345$ & $0.168 \pm 0.17$ & $0.16 \mathrm{NS}$ \\
\hline $\begin{array}{c}2 \text { months } \\
\text { postoperative }\end{array}$ & $0.204 \pm 0.2557$ & $0.164 \pm 0.14$ & $0.5 \mathrm{NS}$ \\
\hline
\end{tabular}

HS: highly significant; NS: non-significan

\section{Changes occurred at each time interval regarding VA in each group}

In the diabetic group 19 (76\%), 20 (80\%), 22 (88\%) eyes showed improvement of their vision at 2 nd week, $1^{\text {st }}$ month and $2^{\text {nd }}$ 
month postoperative respectively. While in the control group most of eyes showed improvement over the follow up period with no one showed deterioration of his vision.

\section{Correlation between the VA (log mar) and MFT (mean foveal thickness)}

There was no statistical significance correlation between BCVA (log MAR) and mean foveal thickness in both groups except at the second month in diabetic patients where the BCVA correlated significantly with MFT.

\section{Correlation between BCVA and AGE, DM duration in diabetic patients}

Preoperative and postoperative Visual acuity has no statistical significance correlation with Age and DM duration.

\section{Correlation between MFT and AGE, DM duration in diabetic patients}

Preoperative and postoperative MFT has no statistical significance correlation with the age and DM duration.

\section{Discussion}

Our concern was the diabetic population as Saudi Arabia is considered as the seventh highest rate in the world in terms of diabetes incidence, with about 3.4 million people having been diagnosed with diabetes in 2015. The recent estimate of the disease showed that $24.4 \%$ of the adult population is suffering from DM [2]. Among diabetic patients, we were able to analyze subsets of eyes that did not have any intraoperative complications or any preoperative macular edema and to stratify theses eyes according to the severity of preoperative retinopathy and the level of glycosylated hemoglobin. We found that the Mean MFT preoperatively, 2 weeks, 1 month and 2 months postoperatively in diabetic patients with diabetic retinopathy (mild, moderate and proliferative DR) was statistically higher compared to patients without DR. There were statistical improvement of visual acuity after 1 and 2 month postoperatively in patient with no DR than those with DR. this finding is consistent with the intuitive expectation of deficient blood retinal barrier function in those patients with more advanced vascular changes resulting from DR [3]. Many previous studies $[4,5]$ showed the high risk of developing macular edema in patients with diabetes and retinopathy but most of the studies did not exclude the patients with preoperative high macular thickness like ours.

Our results showed that after converting the MFT into Log OCT, the MFT in diabetic and control groups was stable postoperatively without any step deterioration. We believe that our study is the unique to use the Log OCT changes in denoting the macular thickness postoperatively. As it was shown that a 1 step log scale change exceeds the measurement error for all degrees of retinal thickness in current instruments, subsequently, a 1-step log Oct change likely represents a real change beyond variability limits. However, Carl and his colleagues concluded that eyes with DME at the baseline and no history of DME treatment had a $4 \%$ incidence of central - involved ME and eyes with DME at the baseline with history of DME treatment had a $21 \%$ incidence at 16 weeks following cataract surgery but they did not record Log OCT changes [6].

\section{Conclusion}

Our study is the unique to use the Log OCT changes in denoting the macular thickness postoperatively. Despite the significant increase of the MFT in the diabetic group of our patients in the 1st month and $2^{\text {nd }}$ month postoperative, the Log OCT was stable in the diabetic and control group without any step of deterioration during the study time. There was no statistical significance difference in the VA (log MAR) between both diabetic patients and control group either in the $2^{\text {nd }}$ week, $1^{\text {st }}$ or $2^{\text {nd }}$ month postoperative. In addition, more than $85 \%$ of diabetics' eyes regain their good vision at the 2nd month post-phacoemulsification.

\section{References}

1. Ferris FL, Miller Km, Glassman AR, Beck RW (2010) Diabetic retinopathy clinical research network. A proposed method of logarithmic transformation of optical coherence tomography data for use in clinical research. Ophthalmology 117: 1512-1516.

2. Ibrahim A Bani (2015) Prevalence, Knowledge, Attitude and Practices of Diabetes mellitus among Jazan Population, Kingdom of Saudi Arabia (KSA). Journal of Diabetes Mellitus 5(2): 115-122.

3. Colin J Chu, Robert L Johnston, Charlotte Buscombe, Ahmed B Sallam, Mohamed Q et al. (2016) Risk factors and incidence of macular edema after cataract surgery: A database study of 81984 Eyes. Ophthalmology 123(2): 316-323

4. Brito PN, Rosas VM, Coentrao LM, Carneiro ÂV, Rocha-Sousa A, et al. (2015) Evaluation of visual acuity, macular status and subfoveal choroidal thickness after cataract surgery in eyes with diabetic retinopathy. Retina 35(2): 294-302

5. Horozoglu FA, Yanyali, Aytug B (2011) Macular thickness after phacoemulsification in previously vitrectomized eyes for diabetic macular edema. Retina 31(6): 1095-1100.

6. Carl W baker, Talat Almukhtar, Neil Bressler, Adam R Glassman et al. (2013) Macular edema after cataract surgery in eyes without preoperative central involved diabetic macular edema. JAMA Ophthalmol 131(7): 870-879. 